\title{
Demand for global health training and experiences among emergency medicine trainees in Australia and New Zealand
}

Rob D Mitchell MBBS (Hons) BMedSc (Hons) MPH\&TM FACEM

Emergency Physician, Emergency \& Trauma Centre, Alfred Hospital, Melbourne PhD Scholar, School of Public Health \& Preventive Medicine, Monash University, Melbourne

Rebecca L Mitchell MBBS MPH\&TM FRANZCOG

Obstetrician \& Gynaecologist, Department of Obstetrics \& Gynaecology, Western Hospital, Melbourne

Georgina A Phillips MBBS FACEM

Emergency Physician, Emergency Department, St Vincent's Hospital, Melbourne PhD Scholar, School of Public Health \& Preventive Medicine, Monash University, Melbourne

Skandarupan Jayaratnam BSc MBBS MPH DipTM\&H FRANZCOG

Staff Specialist, Department of Obstetrics \& Gynaecology, Cairns Hospital, Cairns PhD Scholar, James Cook University, Cairns

Jennifer Jamieson MBBS BBiomedSc MPH\&TM FACEM

Trauma Physician, Trauma Unit, Alfred Hospital, Melbourne

Emergency Physician, Emergency Department, Monash Medical Centre, Melbourne

Gerard M O'Reilly MBBS MPH MBiostat FACEM PhD

Emergency Physician and Head of International Programs, Emergency \& Trauma Centre, Alfred Hospital, Melbourne

Associate Professor, School of Public Health \& Preventive Medicine, Monash University, Melbourne

This is the author manuscript accepted for publication and has undergone full peer review but has not been through the copyediting, typesetting, pagination and proofreading process, which may lead to differences between this version and the Version of Record. Please cite this article as doi: $10.1111 / 1742-6723.13463$

This article is protected by copyright. All rights reserved. 


\section{Corresponding author}

Dr Rob Mitchell

Emergency Physician

Emergency \& Trauma Centre, Alfred Hospital

Commercial Rd

Melbourne VICTORIA 3004

AUSTRALIA

ro.mitchell@alfred.org.au

@robdmitchell

+61402090615

\section{Key words}

Global health, global emergency care, postgraduate medical education, medical education, training, international development

\section{Word count}

2501

\section{Author contributions}

All authors contributed to study design and manuscript review. RDM drafted the manuscript and had overall oversight of the study. RLM was primarily responsive for data analysis.

\section{Competing interests}

The authors have no competing interests to declare.

\section{Funding}

The authors have no funding sources to declare.

\section{Ethics approval}

Ethics approval for this study was obtained through the James Cook University Human Research Ethics Committee (reference H7377). 


\begin{abstract}
Background

Demand for global health $(\mathrm{GH})$ training and experiences among emergency medicine trainees is unknown. The primary objective of the Trainee Interest in Global Health Training (TIGHT) study was to quantify the number of trainees interested in completing a rotation in a resource-limited environment within a low- or middle-income country (LMIC) during their specialty training.
\end{abstract}

\title{
Methods
}

A cross-sectional study of trainees in seven specialty training programs was conducted between August and October 2018. Data were collected using a voluntary, anonymous, selfreporting, web-based survey. This paper describes the results of a planned sub-group analysis of ACEM trainees.

\section{Results}

There were 203 respondents among 2525 ACEM trainees. Although only a small number $(36 / 198,18.2 \%)$ had undertaken a GH experience as a specialty trainee, $85.6 \%(167 / 195)$ were keen to do so. The vast majority of respondents $(179 / 194,87.1 \%)$ were interested or very interested in having their GH experience accredited for training, but $68.9 \%(133 / 193)$ reported that accessing a suitable placement was a barrier. More than $79 \%(147 / 186)$ expressed interest in undertaking an integrated $\mathrm{GH}$ training or fellowship program as an adjunct to specialty training.

\section{Conclusions}

Notwithstanding the limitations of a self-reporting survey with a sub-optimal response rate, there is significant demand for GH training and experiences among ACEM trainees. These findings should inform the development of safe and effective global emergency care training pathways, underpinned by mutually-beneficial, international partnerships with educational and development objectives. 


\section{Introduction}

Global health $(\mathrm{GH})$ is a diverse field of research and practice focussed on improving health and achieving health equity for all people worldwide. ${ }^{1}$ Doctors working in $\mathrm{GH}$ require skills, knowledge and attributes that are not readily acquired through a conventional medical education. GH training (GHT) addresses this gap by equipping health professionals with the competencies necessary for practice in international, resource-limited (RL) and cross-cultural environments. $^{2-4}$

Despite international efforts to increase the visibility of $\mathrm{GH}$ in medical education programs, ${ }^{5-}$ ${ }^{7}$ there is limited integration of GHT with postgraduate medical education (PGME) in Australia and New Zealand (ANZ). ${ }^{8}$ By way of contrast, trainees in North America have the option of participating in domestic GH teaching programs, rotations in RL environments in low- and middle-income countries (LMICs) and post-specialisation fellowships in $\mathrm{GH} .{ }^{9-11}$

Although GH experiences (GHEs) can be extremely beneficial for trainees, ${ }^{2}$ poorly executed deployments pose risks to the host community. ${ }^{8,12,13}$ Formalised GHT helps to mitigate the risk of harm by ensuring that GHEs are undertaken in a rigorous and ethically defensible manner. ${ }^{12}$

\section{Global emergency care}

Global emergency care (GEC) is a subset of GH focussed on reducing preventable morbidity and mortality from time-sensitive disease processes. The field includes emergency care (EC) capacity development in RL environments as well the provision of medical assistance during disasters and complex emergencies. GEC practice encompasses clinical service, education, systems development, quality improvement, leadership, advocacy and research. ${ }^{14}$

Increasingly, there is evidence and recognition of the value of EC in RL settings. Modelling from the World Bank Disease Control Priorities Project estimates that effective EC could save more than one billion disability-adjusted life years (DALYs) each year, and address up to $54 \%$ of all deaths. ${ }^{15,16}$ In the setting of an escalating global burden of non-communicable disease and injury, the World Health Assembly (WHA) has nominated EC as a critical tool to achieve universal health coverage. ${ }^{17-19}$

ACEM fellows and trainees have been involved in GEC activities for several decades. ${ }^{20,21}$ The College has an active GEC Committee, and formal memoranda of understanding with several regional training bodies. ${ }^{18} \mathrm{~A}$ number of ACEM trainees have undertaken accredited placements in RL settings, with anecdotal evidence of a strong, positive effect on their EM training and practice. ${ }^{22}$ 
In recent years, the College has developed formal guidelines for the accreditation of GEC special skills terms, ${ }^{23}$ and a partnership with AVI (formerly Australian Volunteers International) to facilitate trainee deployments and GEC partnerships in the Pacific. ${ }^{22,24}$ Despite reasonably strong uptake of these opportunities, demand for GHT among emergency medicine (EM) trainees in ANZ has not been quantified. ${ }^{25}$ To address this knowledge gap, ACEM participated in the Trainee Interest in Global Health Training (TIGHT) study.

\section{The TIGHT study}

The aim of the TIGHT study was to assess demand for GH careers and training among trainees in selected specialty training programs in ANZ. The objectives were to quantify the number of trainees interested in undertaking a rotation in a RLE in a LMIC during their specialty training, and determine the proportions of trainees interested in undertaking additional work and training in $\mathrm{GH}$. This paper reports the results of a planned sub-group analysis of EM trainees.

\section{Methods}

TIGHT was a cross-sectional study of Australian and New Zealand trainees in selected training programs between August and October 2018. Methods have been described in another paper related to the study. ${ }^{26}$

Trainees were eligible to participate if they were enrolled in a specialty training program with ACEM, the Royal Australian and New Zealand College of Obstetricians \& Gynaecologists, Royal Australasian College of Physicians, Australian and New Zealand College of Anaesthetists or Royal Australian and New Zealand College of Psychiatrists. These colleges indicated their willingness to collaborate in the study at a Specialist Medical Colleges, Associations and Organisations Global Health Meeting in March 2018. ${ }^{26}$

Respondent data were collected using an anonymous, self-reporting, web-based survey conducted via Survey Monkey (Survey Monkey Inc., San Mateo, California, USA). ACEM trainees were invited to participate via the College's electronic newsletter. Participation was voluntary and respondents provided explicit consent prior to undertaking the survey. Ethics approval was obtained through the James Cook University Human Research Ethics Committee (reference H7377). ${ }^{26}$

The survey instrument (Supplementary File 1) was a structured questionnaire developed specifically for the TIGHT study, and underwent pre-testing by a sample of trainees from all participating colleges. Data variables collected included demographics, previous GH experience, and future interest in $\mathrm{GH}$ work and training (including barriers and motivations). A GHE was defined as any professional activity in a RL environment in a LMIC. The majority of items were multiple choice responses, some of which provided an option for free-text 
qualification. Questions regarding future intention to engage in $\mathrm{GH}$ utilised a 5-point Likert scale from very disinterested through to very interested. Analysis was limited to descriptive statistics, with categorical variables described by frequency and proportion. Selected quotes from free-text responses were used to illustrate key findings from descriptive data. ${ }^{26}$

\section{Results}

\section{Respondent demographics}

There were 203 respondents among a trainee population of 2525 , equating to a response rate of 8.0\%. Respondent demographics are described in Table 1. A majority $(187 / 203,92.1 \%)$ had completed their primary medical degree in Australia, New Zealand or another high-income country. Most were in long-term relationships $(140 / 203,69.0 \%)$ and a minority $(56 / 203$, $27.6 \%)$ had children.

\section{INSERT TABLE 1}

Previous global health experience

A significant proportion of respondents had undertaken a GHE as a medical student $(143 / 200$, $71.5 \%)$. A smaller number had done so as a prevocational or specialty trainee $(48 / 198,24.2 \%$ and $36 / 198,18.2 \%$ respectively).

The type of activities undertaken during these experiences varied with stage of training (Figure 1). As medical students, respondents were primarily involved in clinical observation $(111 / 141,78.7 \%)$, but a significant proportion also reported engagement in clinical practice (95/111, 67.4\%). Involvement in development activities (such as quality improvement and training) increased with seniority.

\section{INSERT FIGURE 1}

Among respondents who had undertaken a GHE as a specialty trainee, perceived benefits included improved cultural competence $(34 / 34,100 \%)$, understanding of public health issues $(31 / 34,91.8 \%)$ and medical knowledge (31/34, 91.8\%) [Figure 2].

\section{INSERT FIGURE 2}

Future interest - GH experiences during specialty training

Overall, 167 of 195 respondents (85.64\%) were interested or very interested in undertaking a GHE as a specialty trainee. Most were motivated to provide clinical care $(156 / 166,94.0 \%)$ 
but a substantial majority were also keen to deliver teaching or training (144/166, 86.8\%). A smaller proportion were interested in contributing to quality improvement activities $(90 / 166$, $54.2 \%)$ and policy development (64/166, 38.6\%).

In terms of GHE duration, 60/166 (36.1\%) preferred a placement of between 3 and 6 months, 43/166 (25.9\%) between 6 and 12 months and 36/166 (21.1\%) between 1 and 3 months. Smaller proportions were interested in placements of less than a month $(17 / 166,11.2 \%)$ and more than a year $(11 / 166,6.6 \%)$. Motivations for undertaking these activities are presented in Figure 3.

\section{INSERT FIGURE 3}

The vast majority of respondents $(169 / 194,87.1 \%)$ were interested or very interested in undertaking a GHE accredited for specialty training. The most commonly cited barriers included a lack of suitable positions accredited by ACEM (133/193, 68.9\%), domestic commitments $(130 / 193,67.4 \%)$ and inability to identity an appropriate location and supervisor (106/193, 54.9\%).

Several respondents provided free text comments in relation to future interest and barriers to $\mathrm{GH}$ training. Illustrative quotes are provided in Box 1.

Box 1: Selected free-text comments regarding future interest in GH training

This article is protected by copyright. All rights reserved. 
"GH training and supported placement opportunities would represent a pragmatic commitment from ACEM to pursue a range of its stated aims (eg, equitable access to healthcare)...as such I feel the College should support trainees who desire to further training, placements, or non-clinical work in this area."

"It would be a truly positive change for the College to formally accredit and accept global health as part of a career of an emergency physician. The elements that attracted me to emergency medicine are very much the same for my interest in global health. It would be great if global health were incorporated into the training scheme as an option to encourage these opportunities, rather than it being seen as deviation from the career path and needing to 'catch up' afterward."

"If ACEM could make disaster response or global health a subspecialty for training, I would be in so fast! I've been trying to work out how I can do this for a few years!"

"I think it is really important that ACEM and other colleges encourage and assist trainees to be involved in global health issues. There are a wide variety of benefits that go far beyond the individual. As doctors we should all engage in broader public health issues, including at an international level."

"If a more structured or easily accessible approach to organising global health placements and training can be developed, I would be extremely interested and I believe it would be invaluable for trainees and the wider community."

"I think there is a significant problem with how global health placements are perceived by Australian doctors, (that is) as a way to gain early exposure, develop skill sets and based around short term missions. I would like this to be reframed around needs of LMIC communities and responsible service provision to meet those needs."

Future interest $-\mathrm{GH}$ training

A substantial majority $(167 / 193,86.5 \%)$ were interested or very interested in pursuing further training in $\mathrm{GH}$. Preferred methods of training are displayed in Figure 4. A large proportion of respondents $(147 / 186,79.0 \%)$ were specifically interested or very interested in undertaking an integrated global health training or fellowship program as an adjunct to specialty training. This was defined as a more formal GH training pathway undertaken simultaneously or sequentially with specialty training, incorporating supervised overseas placements, mentoring and a structured education program.

This article is protected by copyright. All rights reserved. 


\section{INSERT FIGURE 4}

Future interest - engagement in GH as a specialist

A majority of respondents (179/191, 93.7\%) were interested or very interested in undertaking $\mathrm{GH}$ work as a specialist. In terms of specific areas of GH practice that respondents were most interested in pursuing, 101/179 (56.4\%) nominated clinical service delivery (eg, clinical placements, short-term clinical missions and disaster response), 67/179 (37.4\%) clinicallyfocussed development activities (eg, teaching, training, mentoring and quality improvement programs), 9/179 (5.0\%) non-clinical development activities (eg, public health projects, policy development and health systems strengthening programs) and 2/179 (1.1\%) research (eg, clinical or non-clinical observational or interventional studies).

In free-text comments, respondents acknowledge that there was some cross-over between these areas. For instance, "At present I'm interested in clinical service delivery, but I think with more experience later in my career I'd be more useful in development activities."

\section{Discussion}

Key findings

TIGHT is the first study to quantify and qualify demand for GH training and careers among specialty trainees in ANZ. This pre-specified sub-group analysis has identified that a large number of EM trainees are interested in pursuing GH experiences and opportunities within and beyond vocational training.

While a majority of respondents had undertaken a GHE as a medical student, less than $20 \%$ had done so as a vocational trainee. This contrasts with the substantial number (85.6\%) that expressed interest in undertaking a GHE prior to the completion of specialty training, suggesting that opportunities and availability to participate in GHEs decline during PGME.

While the vast majority of respondents were interested or very interested in having their GHE accredited for training, nearly $70 \%$ reported that access to a suitable placement was a barrier. Consistent with other GHT data, ${ }^{2}$ competing domestic commitments was also identified as a hurdle. Despite that, over $60 \%$ of respondents would prefer a deployment of at least 3 months, a duration that is likely to confer increased educational and capacity development benefits.

A large number of trainees are also interested in pursuing focussed GH training. Specifically, nearly $80 \%$ were keen to undertake an integrated global health training or fellowship program as an adjunct to specialty training. In conjunction with the extent of interest in GH practice at 
specialist level, there is a strong signal that a significant number of ACEM trainees aspire to a substantive career in GEC.

\section{Implications}

These findings come at a critical time for ACEM and the broader EC community in ANZ. Global demand for effective EC systems is increasing, and significant involvement of ACEM fellows and trainees in EC development activities across the Indo-Pacific region is anticipated. ${ }^{18}$ This will require a pool of suitably trained and experienced GEC practitioners.

Although blueprints for the integration of GHT with EM training and PGME have previously been published, ${ }^{8,25}$ these data should catalyse efforts to further develop training options for specialty trainees. This should include the design, support and evaluation of opportunities for vocational trainees to undertake accredited rotations abroad that are safe, effective and ethically defensible. As part of this process, the barriers identified in this study (such as access to appropriate placements, supervision and leave arrangements) should be addressed.

To minimise the potential for harm (through power imbalances, displacement of local trainees, inadequate supervision and inappropriate clinical practices), these arrangements should be underpinned by mutually beneficial, enduring partnerships between domestic and overseas health services, training institutions and GH agencies. ${ }^{12}$ They should be designed to promote reciprocity and sustainable development, and incorporate safeguards against voluntourism. ${ }^{27}$ Several existing rotations for ACEM trainees meet these criteria (Box 2), and could potentially form part of a comprehensive, longitudinal GHT program (see discussion below).

The TIGHT data also describe a clear role for GH training in emphasising the value of capacity development activities. Over half of the respondents nominated clinical service delivery as their preferred means of future GH involvement. Although there is a place for deployments focussed on service delivery (particularly in the context of disaster response and complex emergencies), more substantial, long-term impact is likely to be achieved through partnerships and assignments focussed on sustainable development. This is in keeping with the WHA's recent call, ${ }^{17,18}$ and the need for GEC practitioners to have broad-based skills in EC systems. ${ }^{14}$

\section{Opportunities and future directions}

In recent months, ACEM has made several positive steps to offer safe and effective GHEs for trainees. First, the College has employed a GEC Manager and Co-ordinator who will play essential roles in the facilitation and prospective accreditation of GEC terms. In concert with this move, several established GEC rotations across the Pacific region ${ }^{24,28}$ (Box 2 ) have now 
been coalesced under the banner of the Visiting Emergency Medicine Registrar Program (VEMRP). The VEMRP, administered by AVI as part of the Australian Volunteers Program, will facilitate ACEM trainee placements in Papua New Guinea, Solomon Islands and Vanuatu. An advantage of the VEMRP model is that it embeds a meaningful GHE within a capacity development framework, while adhering to best practice in international volunteering. ${ }^{27}$ ACEM's remote supervision requirements, as specified in the College's guideline for GEC special skills terms, ${ }^{23}$ help ensure safety for patients, the host community and the trainee.

\title{
Box 2: Examples of best-practice GEC rotations for ACEM trainees
}

\begin{abstract}
Visiting Clinical Lecturer Program (VCLP) in Madang, Papua New Guinea ${ }^{24}$
In the first iteration of this program, ACEM advanced trainees were placed at Divine Word University in Madang, Papua New Guinea and contributed to teaching and training of health extension officer (HEO) students. The program has evolved, and trainees are now based at Modilon General Hospital where they provide clinical care, teach junior doctors and contribute to quality improvement programs. AVI facilitates the partnership through the Australian Government's Australian Volunteers Program.
\end{abstract}

\section{Solomon Islands Graduate Intern Support and Supervision Project (SIGISSP) in Honiara, Solomon Islands ${ }^{28}$}

SIGISSP places advanced trainees with RANZCOG, ACEM and RACP at the National Referral Hospital in Honiara, Solomon Islands for 6-12 month terms. Trainees provide ward-based supervision for junior doctors, contribute to teaching programs for Cubantrained interns and participate in quality improvement activities. The program is facilitated by AVI and funded by the Australian Government's Department of Foreign Affairs and Trade (DFAT).

Like the VCLP (and other positions within the VEMRP), ACEM trainees participating in SIGISSP can apply to have their rotation recognised as a GEC special skills term.

In another positive development, several universities have developed subjects with a GEC focus. For example, the University of Sydney provides an online course centred on critical care in $\mathrm{RL}$ settings, and aims to equip trainees with the skills, knowledge and attributes necessary

This article is protected by copyright. All rights reserved. 
for an initial rotation in an LMIC. ${ }^{29}$ Alfred Health and Monash University also host an annual GEC workshop focussed on essential GEC development skills, including needs assessment, program development, advocacy and research. ${ }^{30}$

These developments are in keeping with previous recommendations for the development of effective GEC training pathways. ${ }^{25,31}$ A report on international models of GHT and their relevance to EM in ANZ counselled against the implementation of North American style, postspecialisation fellowships at individual hospitals, citing a number of challenges specific to the Australasian context (including the modicum of emergency physicians in ANZ with sufficient GEC experience and capacity to facilitate and supervise LMIC rotations). Rather, the report suggested a centralised model comprising mentoring, coursework, supervised field experiences and research as part of a longitudinal, modular $\mathrm{GH}$ training program. ${ }^{31}$ Completion of such a program could culminate in a university or college issued postgraduate certificate or diploma.

\section{Limitations}

Despite the overwhelming interest demonstrated in these data, there is likely to be a large degree of selection bias. As a consequence of the distribution method, the response rate was low, and the study therefore carries all of the limitations of a voluntary, self-reporting survey. With the exception of RANZCOG (which emailed the survey directly to trainees), ${ }^{26}$ the ACEM response rate was the highest of all colleges participating in the TIGHT study.

Although the findings are unlikely to be representative of all trainees, the raw number of trainees expressing demand for accredited $\mathrm{GH}$ rotations during specialty training is substantial, even when considered as a proportion of the total number of trainees enrolled in the ACEM training program.

Another important limitation is the exclusion of EC clinicians in LMICs, particularly with respect to their corresponding attitudes towards GHT. The views of host clinicians and communities are critical to the safe, successful and sustainable implementation of GEC training models.

\section{Conclusion}

This sub-group analysis of the TIGHT study has identified significant demand for GH training and experiences among ACEM trainees. Notwithstanding the limitations of a self-reporting survey with a sub-optimal response rate, there appears to be a critical mass of trainees interested in pursuing GEC practice. 
These findings should inform the development of safe and effective GEC training pathways. Arrangements should leverage ACEM's experience in facilitating GHEs for trainees, and employ a best practice approach to $\mathrm{GH}$ training and volunteering. Ideally, GEC rotations should be incorporated into enduring, mutually-beneficial, international partnerships with educational and development objectives.

With increasing recognition of the value of EC in developing health systems, demand for skilled GEC practitioners is likely to increase. The TIGHT study suggests that there is a large pool of trainees eager to engage in this work. The challenge now is to deliver them a high quality GEC education, such that their future contributions are collaborative and impactful.

\section{References}

1. Koplan JP, Bond TC, Merson MH, et al. Towards a common definition of global health. Lancet. 2009;373(9679):1993-1995. doi:10.1016/S0140-6736(09)60332-9

2. Drain PK, Holmes KK, Skeff KM, Hall TL, Gardner P. Global health training and international clinical rotations during residency: current status, needs, and opportunities. Acad Med. 2009;84(3):320-325. doi:10.1097/ACM.0b013e3181970a37

3. Battat R, Seidman G, Chadi N, et al. Global health competencies and approaches in medical education: a literature review. BMC Med Educ. 2010;10(1):94. doi:10.1186/1472-6920-10-94

4. Sawleshwarkar S, Negin J. A Review of Global Health Competencies for Postgraduate Public Health Education. Front Public Heal. 2017;5:46. doi:10.3389/fpubh.2017.00046

5. Frenk J, Chen L, Bhutta ZA, et al. Health professionals for a new century: transforming education to strengthen health systems in an interdependent world. Lancet. 2010;376(9756):1923-1958. doi:10.1016/S0140-6736(10)61854-5

6. Bryant JH, Velji A. Global Health and the Role of Universities in the Twenty-First Century. Infect Dis Clin North Am. 2011;25(2):311-321. doi:10.1016/j.idc.2011.02.012

7. Arthur M, Battat R, Brewer TF. Teaching the Basics: Core Competencies in Global Health. Infect Dis Clin North Am. 2011;25:347-358. doi:10.1016/j.idc.2011.02.013

8. Mitchell RD, Jamieson JC, Parker J, Hersch FB, Wainer Z, Moodie AR. Global health training and postgraduate medical education in Australia: the case for greater integration. Med J Aust. 2013;198(6):316-319. doi:10.5694/mja12.11611

9. Kerry VB, Walensky RP, Tsai AC, et al. US medical specialty global health training and the global burden of disease. J Glob Health. 2013;3(2):020406. doi:10.7189/jogh.03.020406

10. Hau DK, Smart LR, DiPace JI, Peck RN. Global health training among U.S. residency specialties: a systematic literature review. Med Educ Online. 2017;22(1):1270020. doi:10.1080/10872981.2016.1270020

11. Nelson B, Izadnegahdar R, Hall L, Lee PT. Global Health Fellowships: A National, CrossDisciplinary Survey of US Training Opportunities. J Grad Med Educ. 2012;4(2):184- 
189. doi:10.4300/JGME-D-11-00214.1

12. Crump JA, Sugarman J. Ethics and Best Practice Guidelines for Training Experiences in Global Health. Am J Trop Med Hyg. 2010;83(6):1178-1182.

doi:10.4269/ajtmh.2010.10-0527

13. Bauer I. More harm than good? The questionable ethics of medical volunteering and international student placements. Trop Dis Travel Med vaccines. 2017;3:5.

doi:10.1186/s40794-017-0048-y

14. Phillips G, Nielson A, Mitchell R. Global Emergency Care \& Disaster Health. In: Working in Global Health: An Introduction for Students and Health Practitioners. London: SAGE Publications; 2015.

15. Thind A, Hsia R, Mabweijano J, Hicks ER, Zakariah A, Mock CN. Prehospital and Emergency Care. In: Debas H, Donkor P, Gawande A, Jamison D, Kruk M, Mock C, eds. Disease Control Priorities. Volume 1: Essential Surgery. 3rd ed. Washington DC: The World Bank; 2015. doi:10.1596/978-1-4648-0346-8_CH14

16. Reynolds TA, Sawe H, Rubiano AM, Shin S Do, Wallis L, Mock CN. Strengthening Health Systems to Provide Emergency Care. In: Jamison DT, Gelband H, Horton S, et al., eds. Disease Control Priorities. Volume 9: Improving Health and Reducing Poverty. 3rd ed. Washington DC: World Bank Group; 2018. doi:10.1596/978-1-4648-0529-5

17. World Health Assembly. Resolution 72.31. Emergency care systems for universal health coverage: ensuring timely care for the acutely ill and injured.

http://apps.who.int/gb/ebwha/pdf_files/WHA72/A72_ACONF1-en.pdf?ua=1. Accessed June 7, 2019.

18. Mitchell R, Phillips G, O'Reilly G, Creaton A, Cameron P. World Health Assembly Resolution 72.16: What are the implications for the Australasian College for Emergency Medicine and emergency care development in the Indo-Pacific? Emerg Med Australas. 2019;31(5):696-699. doi:10.1111/1742-6723.13373

19. Anderson PD, Suter RE, Mulligan T, Bodiwala G, Razzak JA, Mock C. World Health Assembly Resolution 60.22 and its importance as a health care policy tool for improving emergency care access and availability globally. Ann Emerg Med. 2012;60(1):35-44.e3. doi:10.1016/j.annemergmed.2011.10.018

20. O'Reilly GM, Curry C. International emergency medicine: Building on a strong information-sharing foundation. Emerg Med Australas. 2010;22(6):488-492. doi:10.1111/j.1742-6723.2010.01343.x

21. Cameron P, Hobgood C, Mulligan T. Developments in international emergency medicine. Emerg Med Australas. 2009;21:339-341. doi:10.1111/j.1742-

6723.2009.01211.x

22. Thurtle N, Phillips G, Keage J, Wallis A, Mitchell R, Jamieson J. Perspectives on working and training in global health and international emergency medicine. Emerg Med Australas. 2014;26(6):635-638. doi:10.1111/1742-6723.12322

23. Australasian College for Emergency Medicine. Accreditation Guidelines. Special Skills Placement - Global Emergency Care. https://acem.org.au/getmedia/41566a82-57e1- 
48f9-82f6-6cfbcdd33b55/AC472-Global_Emergency_Care_SSP_Guidelines_v011.aspx. Accessed November 9, 2019.

24. Phillips GA, Hendrie J, Atua V, Manineng C. Capacity building in emergency care: An example from Madang, Papua New Guinea. Emerg Med Australas. 2012;24(5):547552.

25. Jamieson J, Mitchell R, Perry A, Rotella J, O’Reilly G, Reilly GO. Training in global health and international emergency medicine: Where to next? Emerg Med Australas. 2014;26(6):630-634. doi:10.1111/1742-6723.12321

26. Mitchell R, Mitchell R, Phillips G, Jayaratnam S. Demand for global health training among obstetric \& gynaecology trainees in Australia \& New Zealand: results of the TIGHT study. Aust N Z J Obstet Gynaecol. (in press).

27. Australian Council for International Development. ACFID Practice Note. Responsible International Volunteering for Development.

https://acfid.asn.au/sites/site.acfid/files/resource_document/ACFID Practice NoteVolunteering for International Development.pdf. Accessed November 9, 2019.

28. AVI. Solomon Islands Graduate Intern Support and Supervision Project. https://www.avi.org.au/work-with-avi/case-studies/solomon-islands-graduateinternship-and-supervision-support-project/. Accessed January 5, 2019.

29. The University of Sydney. Resource Limited Critical Care - CRIT5014. https://sydney.edu.au/courses/units-of-study/2020/crit/crit5014.html. Accessed November 9, 2019.

30. Alfred Health Emergency Education. Global Emergency Care Conference. https://emergencyeducation.org.au/global-programs/gecc/. Accessed November 28, 2019.

31. Mitchell R. Postgraduate training in global emergency care: international experience and potential models for Australasia. Report to the Winston Churchill Memorial Trust. https://www.churchilltrust.com.au/media/fellows/Mitchell_Robert_2014_Postgradu ate_training_in_global_emergency_care.pdf. Published 2015. Accessed January 7, 2018. 
Figure 2: Benefits of GH experiences during specialty training

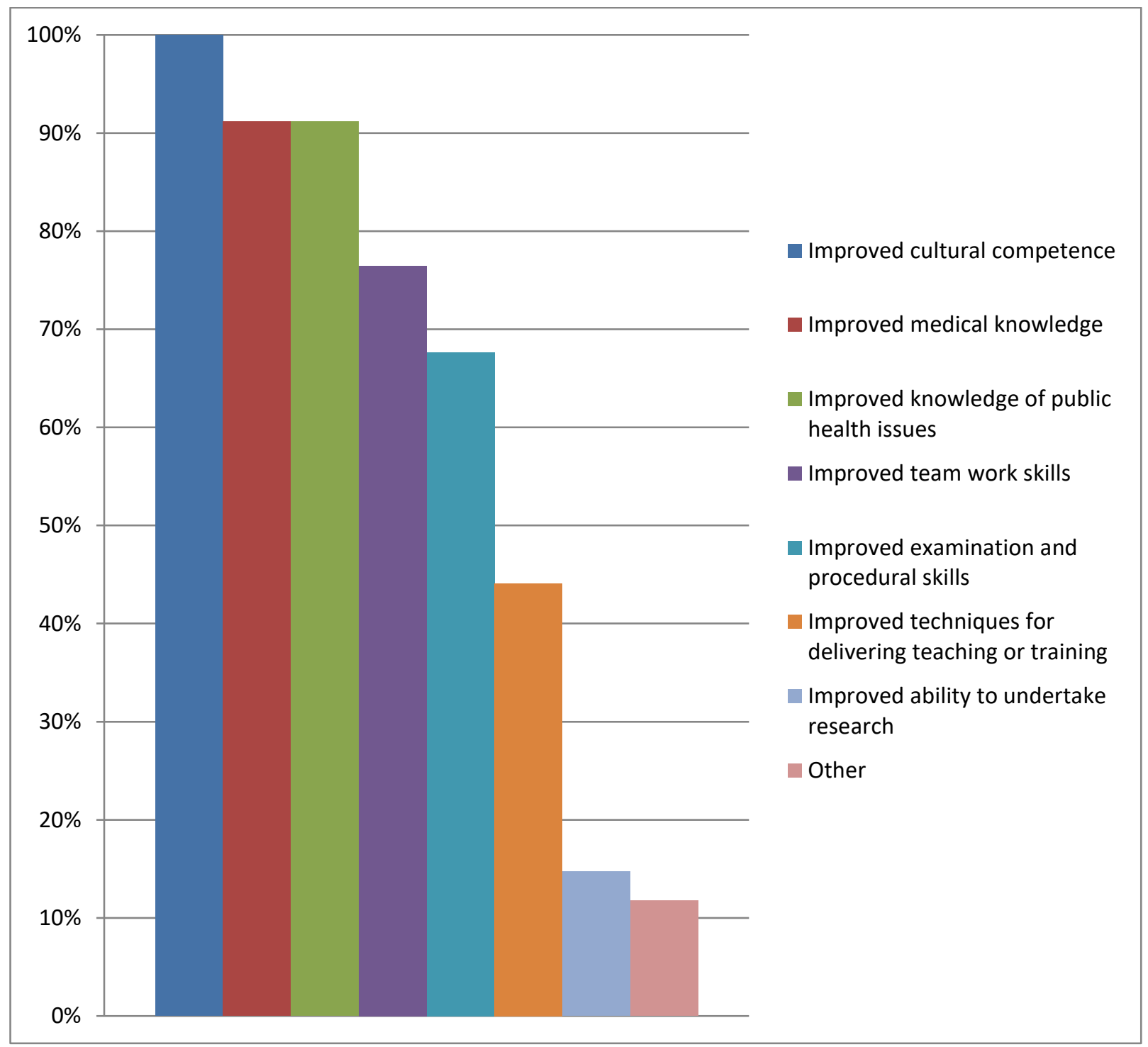

*responses do not tally $100 \%$ because respondents could choose multiple answers

This article is protected by copyright. All rights reserved. 
Figure 3: Motivations for undertaking a GHE during specialty training

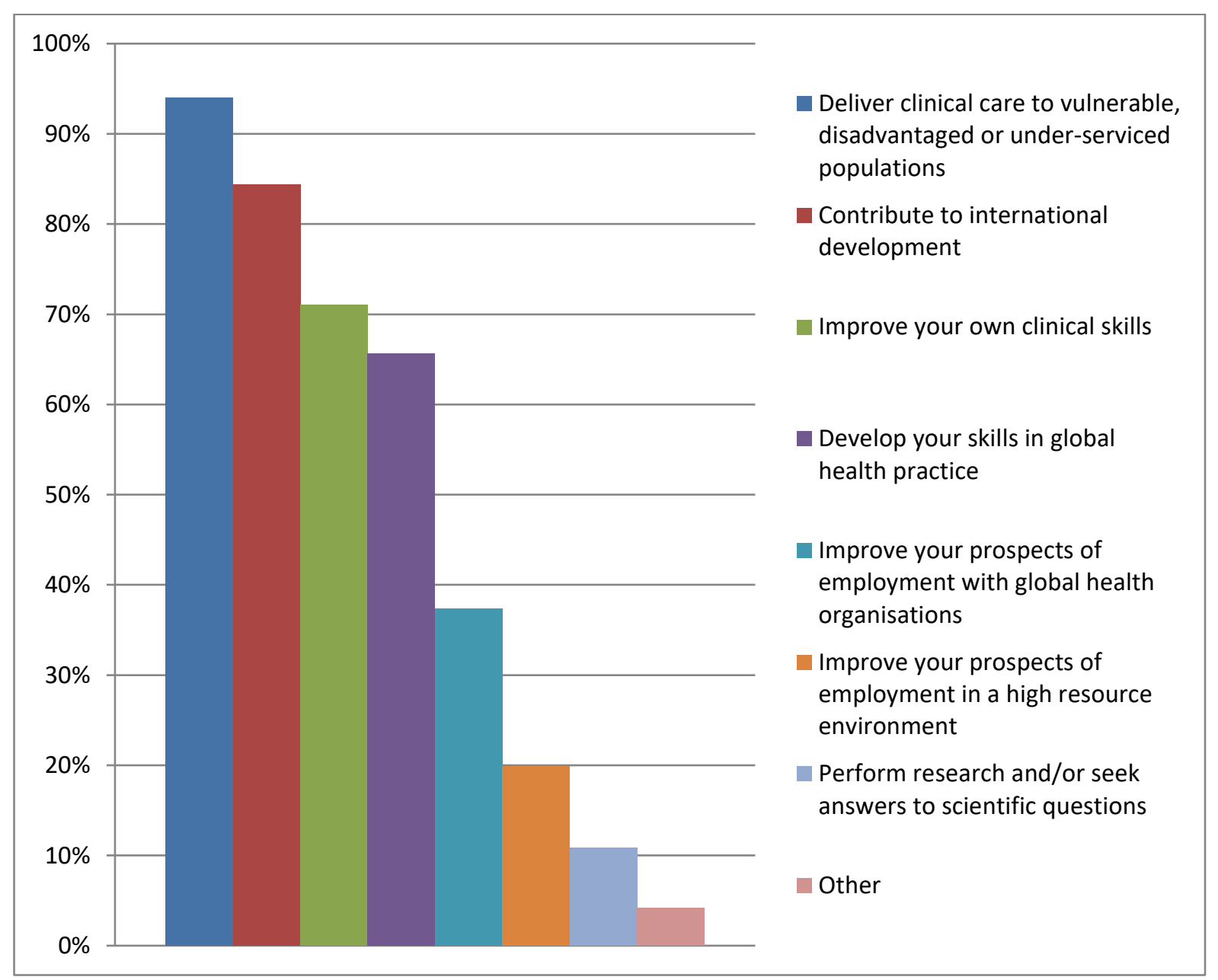

*responses do not tally $100 \%$ because respondents could choose multiple answers

This article is protected by copyright. All rights reserved. 


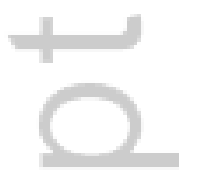


Figure 4: Interest in various methods of GH training

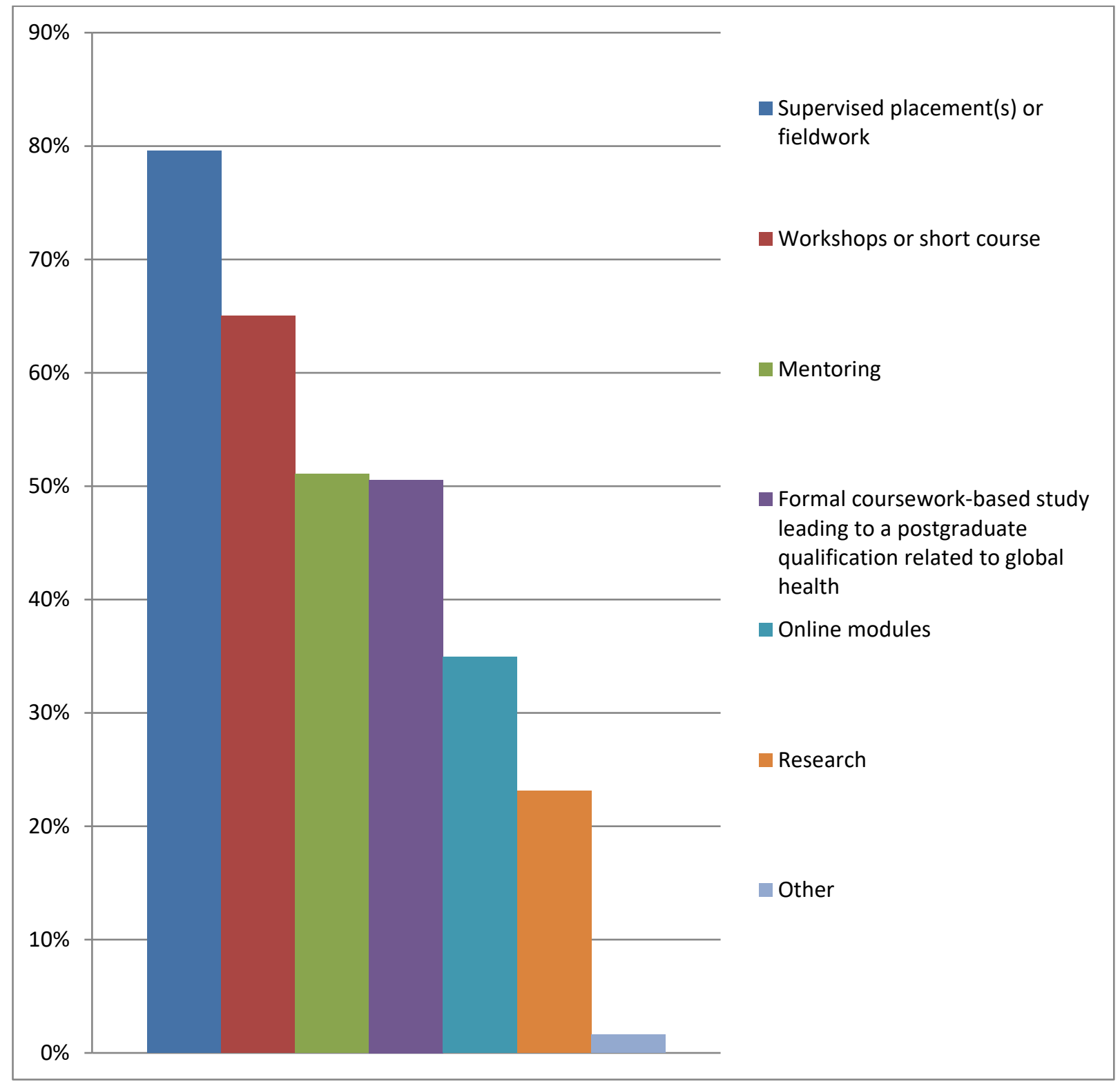

*responses do not tally $100 \%$ because respondents could choose multiple answers

This article is protected by copyright. All rights reserved. 
Figure 1: Activities undertaken during previous GH experiences

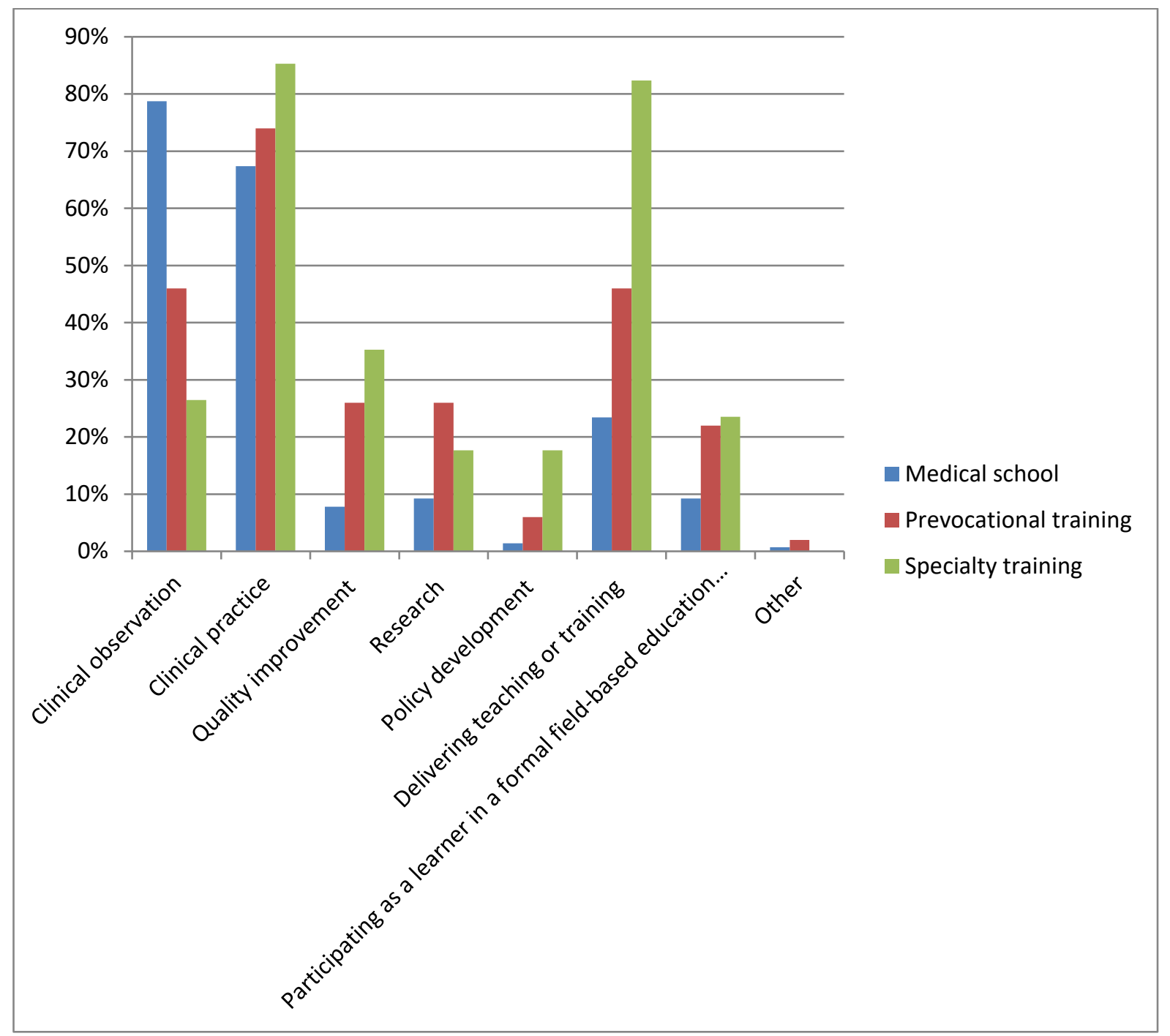

*responses do not tally $100 \%$ because respondents could choose multiple answers

This article is protected by copyright. All rights reserved. 


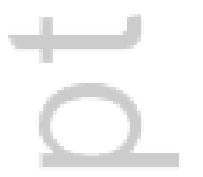


Figure 4: Interest in various methods of GH training

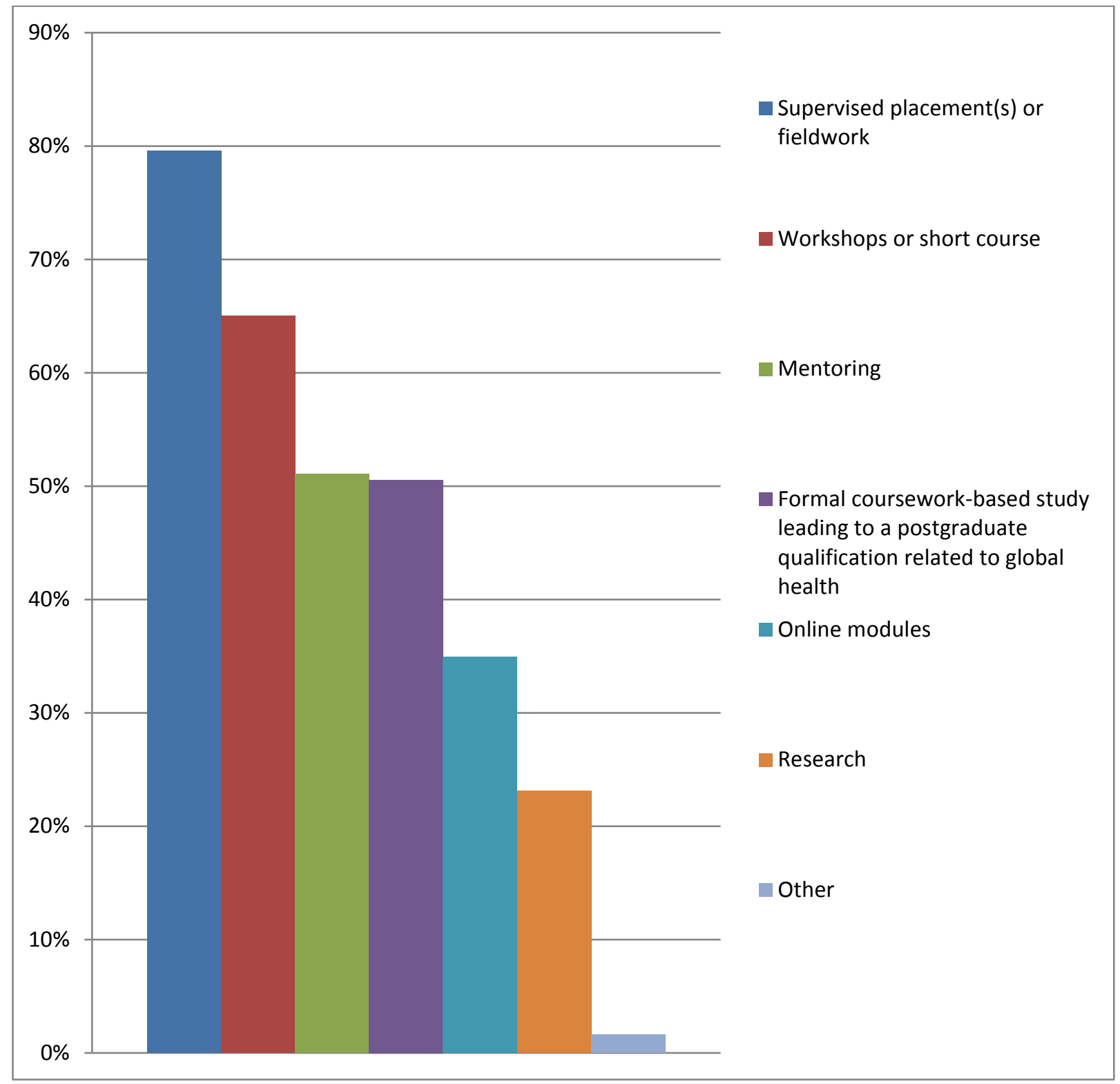

*responses do not tally $100 \%$ because respondents could choose multiple answers

This article is protected by copyright. All rights reserved. 
Table 1: Respondent demographics

\begin{tabular}{|c|c|c|c|}
\hline & \multicolumn{2}{|c|}{ ACEM trainee respondents } \\
\hline & & $\mathrm{n}$ & $\%$ \\
\hline \multicolumn{2}{|l|}{ Respondents } & 203 & 8.0 \\
\hline \multirow{2}{*}{ Training year } & $1-3$ & 126 & 62.1 \\
\hline & $4-6$ & 77 & 37.9 \\
\hline \multirow{4}{*}{ Age } & $25-29$ & 52 & 25.6 \\
\hline & $30-34$ & 103 & 50.7 \\
\hline & $35-40$ & 38 & 18.7 \\
\hline & $\geq 40$ & 10 & 4.9 \\
\hline Gender & Female & 120 & 59.1 \\
\hline \multirow[b]{3}{*}{ Relationship } & Single & 48 & 23.6 \\
\hline & $\begin{array}{l}\text { Short-term } \\
\text { relationship }\end{array}$ & 15 & 7.4 \\
\hline & $\begin{array}{l}\text { Long-term } \\
\text { relationship, } \\
\text { de facto or } \\
\text { married }\end{array}$ & 140 & 69.0 \\
\hline Children & Yes & 56 & 27.6 \\
\hline \multirow{3}{*}{$\begin{array}{l}\text { Country of primary } \\
\text { medical degree }\end{array}$} & $\begin{array}{l}\text { Australia or } \\
\text { New } \\
\text { Zealand }\end{array}$ & 129 & 63.5 \\
\hline & $\begin{array}{l}\text { Other high- } \\
\text { income } \\
\text { country }\end{array}$ & 58 & 28.6 \\
\hline & $\begin{array}{l}\text { Low- or } \\
\text { middle- } \\
\text { income } \\
\text { country }\end{array}$ & 16 & 7.9 \\
\hline
\end{tabular}

This article is protected by copyright. All rights reserved. 


\section{University Library}

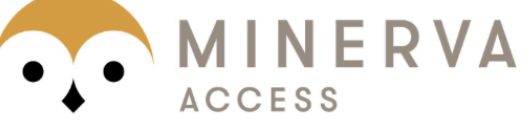

A gateway to Melbourne's research publications

Minerva Access is the Institutional Repository of The University of Melbourne

Author/s:

Mitchell, RD;Mitchell, RL;Phillips, GA;Jayaratnam, S;Jamieson, J;O'Reilly, GM

Title:

Demand for global health training and experiences among emergency medicine trainees in Australia and New Zealand

Date:

2020-02-17

\section{Citation:}

Mitchell, R. D., Mitchell, R. L., Phillips, G. A., Jayaratnam, S., Jamieson, J. \& O'Reilly, G. M. (2020). Demand for global health training and experiences among emergency medicine trainees in Australia and New Zealand. EMERGENCY MEDICINE AUSTRALASIA, 32 (2), pp.327-335. https://doi.org/10.1111/1742-6723.13463.

Persistent Link:

http://hdl.handle.net/11343/275429 